\title{
Reading comprehension in Spanish language and literature manuals of the second cycle of Elementary Education
}

Número 5.

Enero de 2016

Beatriz Sánchez Hita

Universidad de Cádiz

\begin{abstract}
:
This paper deals with the readings and reading comprehension exercises from a representative set of Spanish language and Spanish literature textbooks, used in the second cycle of Elementary Education in Andalusia. Specifically, we attend on the typology of the texts, the selected authors and books and the exercises focused on the readings. The objective of the study is the determination of how the proposed texts help in the reading comprehension and which are the better ways to work with them.
\end{abstract}

Keywords

Reading comprehension, texts corpus, Elementary Education, Spanish language and literature 


\section{Introducción}

Como han puesto de relieve numerosos estudios, leer es un proceso mucho más complejo que decodificar un texto escrito, pues supone una actividad clave para desenvolverse en sociedad y acceder al conocimiento; esto hace imprescindible la correcta interpretación de lo leído. Mendoza, López y Martos refiriéndose a la enseñanza-aprendizaje de la lectoescritura señalan que esta es el "eje en torno al cual gira el desarrollo cognitivo de la persona" (1996, p. 285), por su parte Galera (2003, pp. 221 y 229) constata la presencia de la lectura como actividad fundamental en las aulas, cuyo trabajo debe estar presente en todas las áreas y en la que la comprensión constituye un aspecto fundamental.

En su estudio denuncia Galera cómo pese a los cambios introducidos por la LOGSE, que en lo que toca al tema que aquí nos interesa supusieron la inclusión de una mayor variedad de textos - aunque se continuó abusando de los literarios-, la comprensión lectora se siguió realizando mediante actividades que solo propiciaban la comprensión literal de lo escrito, dejando al margen la interpretación, sin que se fomentase asimismo la diferenciación entre la lectura que se hace por placer y aquella otra de carácter obligatorio sobre la que se realizan una serie de ejercicios. A partir de estas ideas, destaca Galera la importancia no solo de afrontar la comprensión desde la diversidad de materiales adaptados a las destrezas de los destinatarios, sino que otorga un papel principal al trabajo de los mismos, que debe realizarse a través de preguntas variadas: de tipo recordatorio, de inferencia o de carácter metacognitivo; todo ello sin descuidar la comprensión lectora como proceso global que puede propiciar el acercamiento a la lectura como fuente de disfrute (2003, pp. 237-238).

Desde estas consideraciones hemos querido observar en qué medida la LOE — que destacaba la importancia de trabajar la lectura de manera transversal y la convertía en un elemento clave para el desarrollo de las competencias básicas (Romero, 2009, pp. 191-192)_modificó o mejoró la manera de afrontar la comprensión lectora en las aulas, valorando los recursos propuestos para trabajarla en los manuales de Lengua Castellana y Literatura ${ }^{1}$. De

\footnotetext{
${ }^{1}$ La LOMCE sigue otorgando un papel fundamental a la lectura como elemento de acceso al conocimiento. De hecho, cuando se observan los objetivos para la etapa de Educación Primaria propuestos por la LOE y la LOMCE se aprecian bastantes coincidencias, pese a la modificación del artículo 16, punto 2. Así la LOE recoge lo siguiente: "La finalidad de la educación primaria es proporcionar a todos los niños y niñas una educación que permita afianzar su desarrollo personal y su propio bienestar, adquirir las habilidades culturales básicas relativas a la expresión y comprensión oral, a la lectura, a la escritura y al cálculo, así como desarrollar las habilidades sociales, los hábitos de trabajo y estudio, el sentido artístico, la creatividad y la afectividad" (BOE, $\mathrm{n}^{\circ} 106$ de 4 de mayo de 2006, p. 17168); mientras en la LOMCE se lee: "La finalidad de la Educación Primaria es facilitar a los alumnos y alumnas los aprendizajes de la expresión y comprensión oral, la lectura, la escritura, el cálculo, la adquisición de nociones básicas de la cultura, y el hábito de convivencia así como los de estudio y trabajo, el sentido artístico, la creatividad y la afectividad, con el fin de garantizar una formación integral que contribuya al pleno desarrollo de la personalidad de los alumnos y alumnas y de prepararlos para cursar con aprovechamiento la Educación Secundaria Obligatoria" (BOE, no 295 de 10 de diciembre de 2013, p. 97870). De igual modo, cuando se desarrolla el currículo para la etapa, y en concreto cuando se trata del correspondiente al área de Lengua Castellana y Literatura se precisa lo siguiente: "El área de Lengua Castellana y Literatura en la Educación Primaria tiene como finalidad el desarrollo de las destrezas básicas en el uso de la lengua: escuchar, hablar, leer y escribir, de forma integrada. La adquisición de estas destrezas comunicativas solo puede conseguirse a través de la lectura de distintas clases de textos, de su comprensión y de la reflexión sobre ellos" (BOE, $\mathrm{n}^{\circ} 52$ de 1 de marzo de 2014, p. 19378).
}

ISL, vol. 5, 2016, págs. 19-35 ISNN: 2340-8685
Sánchez Hita, B (2016): Reading comprehension in Spanish language and literature manuals of the second cycle of Elementary Education, Investigaciones Sobre Lectura, 5, 19-35. 
manera concreta, se han tenido presentes aquí los libros del segundo ciclo de Educación Primaria empleados por tres grupos educativos concertados de Andalucía: Sagrada Familia, Salesianos y Jesús María y José, donde el pasado curso se emplearon, por orden, los textos de Anaya (En línea), Edebé (Píxel) y Edelvives (Pixépolis) ${ }^{2}$.

En las siguientes páginas se ofrecerán, en primer lugar, los porcentajes que suponen la lectura y las actividades en torno a ella respecto al total de contenidos en cada uno de los manuales, indicando ahí qué tipo de textos integra dicha sección y, en el caso de los literarios, precisando qué géneros son los que se ven representados. A partir de estos datos y atendiendo a las actividades propuestas para el trabajo de estos escritos se valorará en qué medida se fomenta un correcto desarrollo de la comprensión lectora o qué elementos son susceptibles de mejora ${ }^{3}$.

\section{Manuales y contenidos para a lectura}

Aunque cada uno de los manuales analizados presenta una selección diferente de autores y textos, todos coinciden en otorgar a la sección de lectura y comprensión lectora un lugar fundamental, no solo por su posición - generalmente introduce las unidades, salvo en el caso de Píxel de Edebé donde aparece tras la actividad de expresión oral con la que dan comienzo los temas- sino, sobre todo, por sus mayores dimensiones, ya que en los tres casos supone casi el 25\% respecto al total de páginas - porcentaje que aumenta si se tiene en cuenta que otras secciones como las de vocabulario u ortografía suelen basarse en elementos presentes en la lectura inicial ${ }^{4}$. De manera gráfica la distribución indicada quedaría representada del siguiente modo:

\footnotetext{
${ }^{2}$ Se toman como referencia los empleados en el curso 2014/2015, adaptados a lo dispuesto en el currículo LOE. Tras la consulta de los nuevos materiales y a través de conversaciones con algunos docentes, hemos podido constatar que las variaciones más significativas tienen que ver con la metodología de trabajo donde se han introducido más actividades de tipo colaborativo, mientras que los contenidos en sí apenas han sufrido variaciones. No obstante, este es un aspecto que requiere aún un análisis más detallado.

${ }^{3}$ Existen interesantes estudios sobre los autores y textos empleados en los manuales de Lengua Castellana y Literatura como el dirigido por Tejerina (2004) o el de Moreno (2004) sobre las lecturas empleadas en Educación Secundaria Obligatoria en Cantabria y sobre la poesía en el último cuarto del siglo XX, respectivamente. Para la valoración de las actividades de comprensión lectora se tienen en cuenta los trabajos de Gracia et al. (2009) además de los estudios de referencia de Cassany et al. (1994) y Mendoza Fillola (2008).

${ }^{4}$ Se han tenido en cuenta tanto los textos como las actividades.
} 


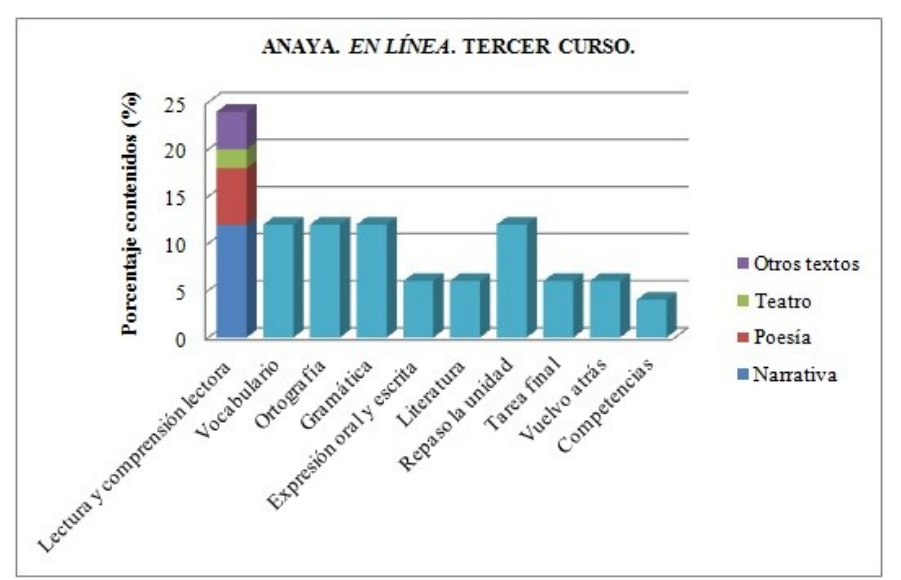

Fig. 1. Reparto y porcentaje de secciones en Anaya En línea, tercer curso de Educación Primaria

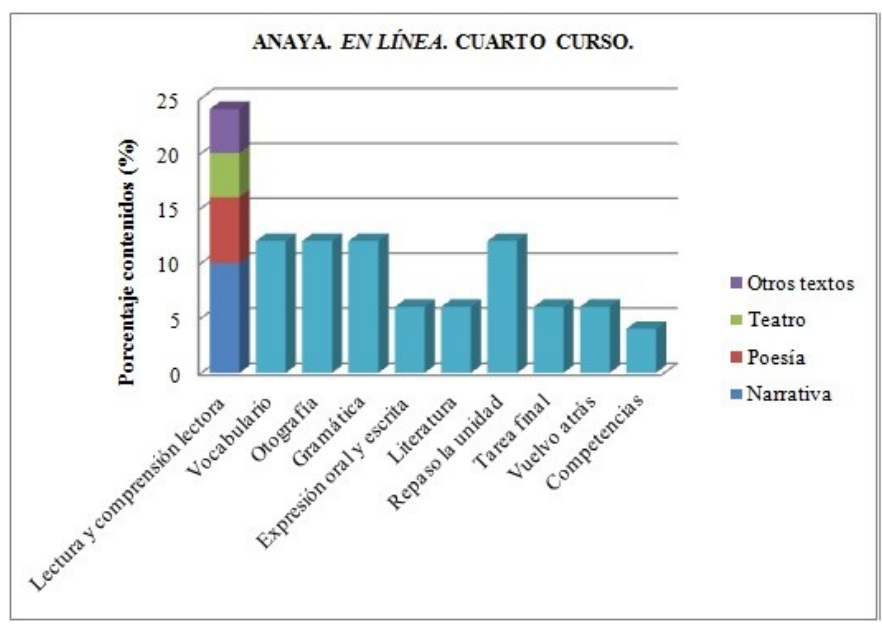

Fig. 2. Reparto y porcentaje de secciones en Anaya En línea, cuarto curso de Educación Primaria

Como puede apreciarse, en el caso de En línea la mayor parte de los textos ofertados como lectura pertenecen al género literario y en concreto se trata de textos narrativos, aunque se incluye también poesía y teatro - aumentando la presencia de este último género en el cuarto curso-; el resto de textos son escritos divulgativos, con los que se quiere despertar la curiosidad del alumno por ciertos temas como la alimentación, los viajes o la historia. En lo que respecta a los contenidos literarios debe precisarse que, a excepción de la poesía, lo que se ofrece son fragmentos de obras más amplias de autores de Literatura Infantil y Juvenil [en adelante LIJ] de ámbito nacional e internacional: Daniel Nesquens, Cornelia Funke, Jordi Sierra i Fabra, Pedro Mañas, Consuelo Arnijo, Mónica Rodríguez, José González Torices, Ana María Shua, Montserrat del Amo, Carmen Gil, Marinella Terzi, Ana Alonso, María Cristina Ramos, Isabel Agüera, Joles Sennell [seudónimo de Pepe Albanell], Robert Louis Stevenson, Pedro Mañas o Rafael Alcaraz y en una ocasión se incluye un fragmento de la adaptación de El Quijote hecha por Rosa Navarro Durán ${ }^{5}$.

\footnotetext{
${ }^{5}$ Por motivos de espacio se incluye como anexo la relación completa de textos, obras y autores.
}

ISL, vol. 5, 2016, págs. 19-35 ISNN: 2340-8685
Sánchez Hita, B (2016): Reading comprehension in Spanish language and literature manuals of the second cycle of Elementary Education, Investigaciones Sobre Lectura, 5, 19-35. 


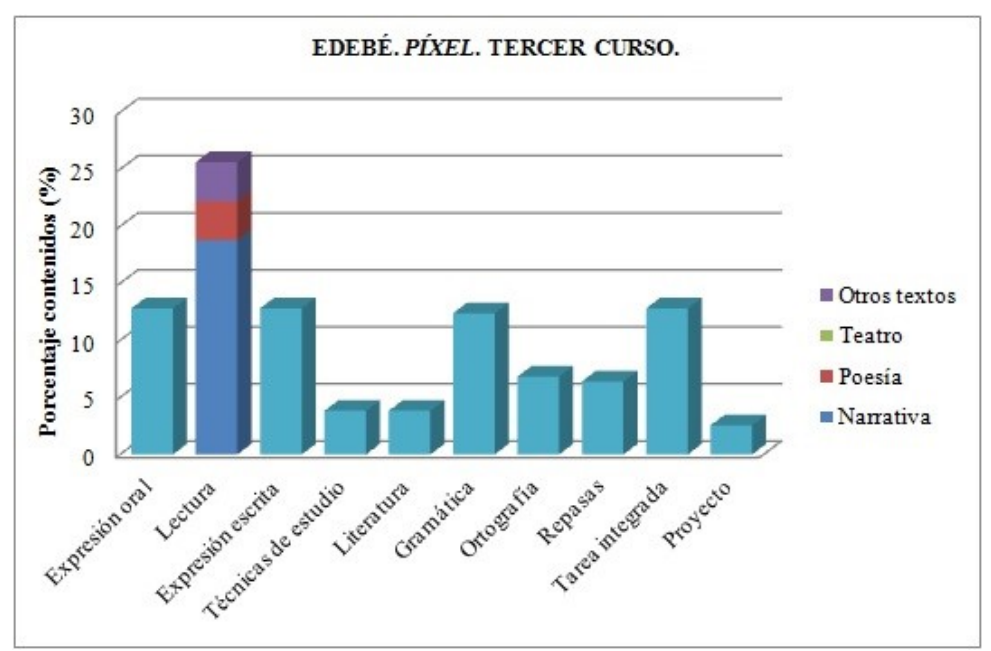

Fig. 3. Reparto y porcentaje de secciones en Edebé Píxel, tercer curso de Educación Primaria

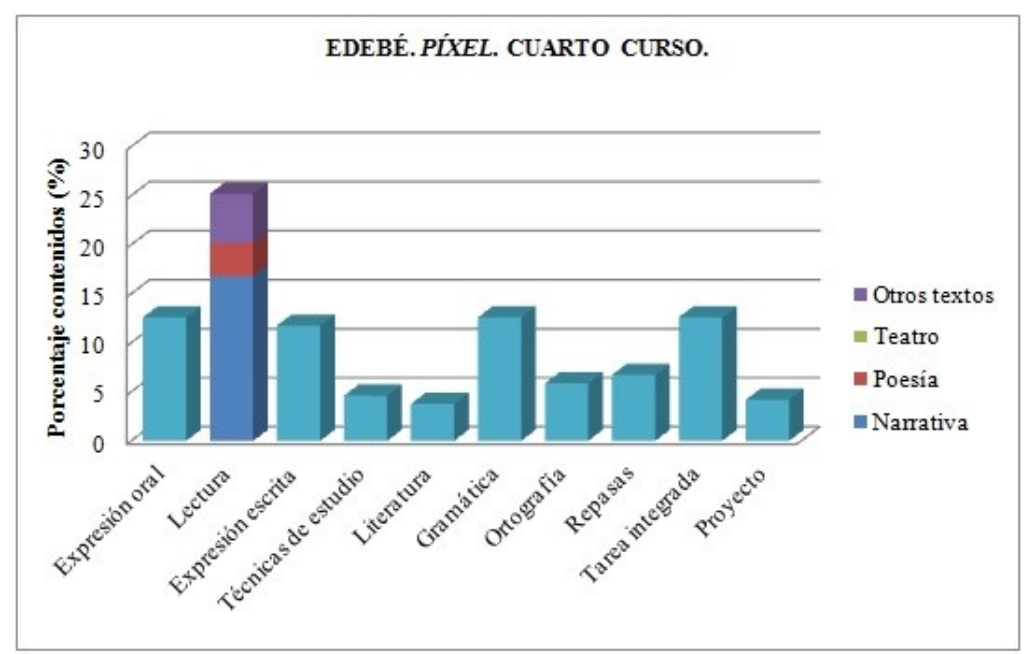

Fig. 4. Reparto y porcentaje de secciones en Edebé Píxel, cuarto curso de Educación Primaria

En el caso de Píxel hay que destacar que en la sección de lectura predominan los textos narrativos, aunque tampoco faltan dos y tres textos divulgativos en cada uno de los volúmenes, y en dos unidades es la poesía la que abre los temas y en torno a la que giran las actividades de comprensión. La procedencia de los textos literarios es diversa, en varias ocasiones se parte de las adaptaciones hechas de obras clásicas por Rosa Navarro Durán, se incluyen textos de tradición oral, así como obras no escritas para niños pero que han sido aceptadas por ellos como las creaciones poéticas de Juan Ramón Jiménez y Federico García Lorca y composiciones realizadas por autores de LIJ como Gabriel García de Oro, Patxi Zubizarreta y Juan Cruz Iguerabide, David Nel-lo, Enric Lluch, Gloria Sánchez, Xelis de Toro, Roberto Santiago, Anna Cabeza, Jordi Sierra y Fabra, Isabel Córdova, Antonio Manuel Fabregat, Ana Martín Pérez, Rodirgo Muñoz Ávila, Claudia Larraguibel o Xabier Mendiguen. 


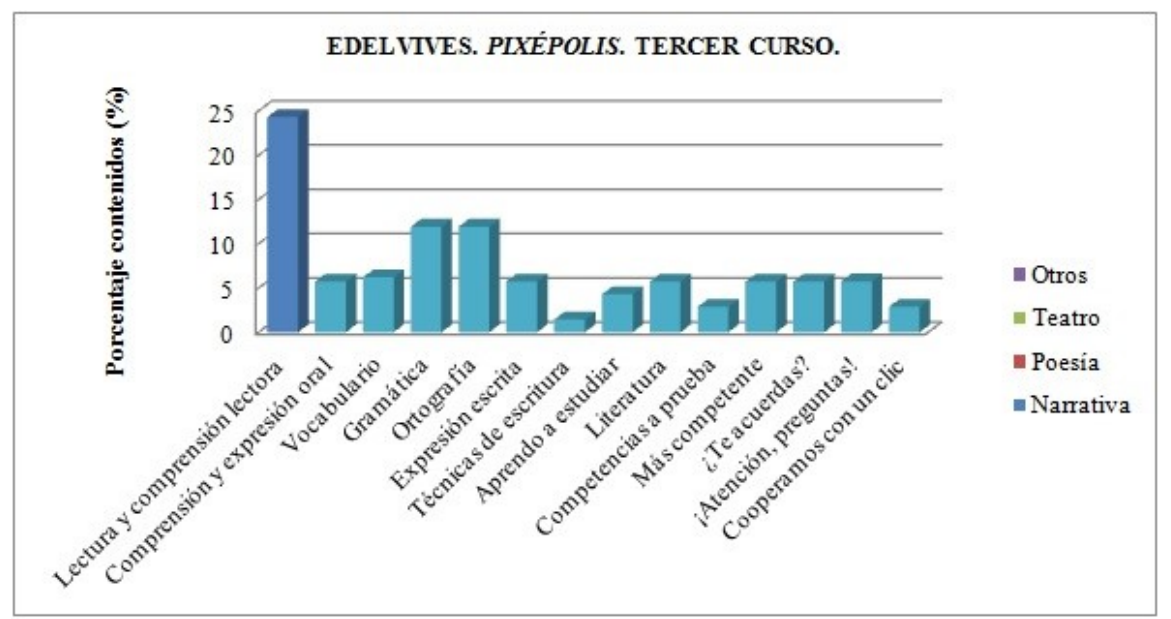

Fig. 5. Reparto y porcentaje de secciones en Edelvives Pixépolis, tercer curso de Educación Primaria

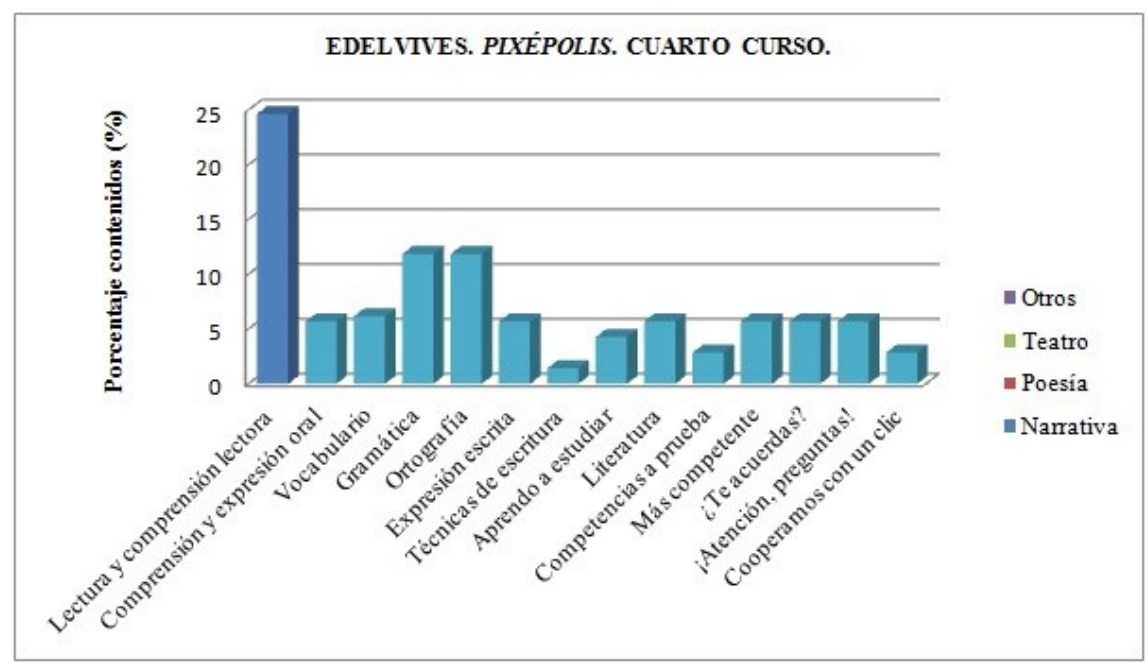

Fig. 6. Reparto y porcentaje de secciones en Edelvives Pixépolis, cuarto curso de Educación Primaria

En Pixépolis todos los textos que se ofrecen como lectura inicial son obras narrativas escritas ex profeso para la citada edición por autores de LIJ. Firman las lecturas: Antonio Vicente Lucerga, Roberto Aliaga Sánchez, Alfredo Gómez Cerdá, Pepe Maestro, José García Oliva y Pablo Albo. Los textos se ofrecen siempre completos, lo que favorece en principio su comprensión (Gracia, Jiménez, Rodrigo, Romero, Salvador y Sibón, 2009, p.13).

De lo visto hasta aquí se deduce que la oferta editorial analizada centra el trabajo de la comprensión lectora mayoritariamente en una recopilación de textos literarios, en los que el narrativo es el género más habitual, tal y como indicase Galera refiriéndose a los materiales empleados en la LOGSE. No obstante, este hecho podría justificarse en la utilidad de este tipo de textos y de otros de carácter narrativo para el trabajo de la comprensión lectora en los dos primeros ciclos de Educación Primaria, como apuntan Gracia et al. (2009, pp. 13 y 17), aunque esto no debería significar la ausencia de otros 
materiales — salvo que se trabajen desde el punto de vista de la comprensión lectora en otras áreas-o la reducción de la literatura al género narrativo.

En función de lo visto, nos inclinamos a pensar que, de manera general, en los manuales analizados la comprensión lectora se vincula al desarrollo de la competencia literaria, que a su vez se ve complementada por los contenidos de la sección "Literatura". En los casos de Anaya y Edelvives parece predominar en la selección de obras un canon basado en la LIJ, que según Mendoza (2002) ayuda al niño a introducirse en el mundo "de la cultura literaria y de la cultura en general" a través de creaciones que responden a sus intereses y capacidades; mientras que en lo que se refiere a Edebé predominaría un canon formativo, encaminado a mostrar la diversidad del hecho literario, sin que se descuide la presencia de autores de $\mathrm{LIJ}^{7}$. Sea como sea, parece que en los últimos años se ha conseguido dar respuesta al requerimiento de incluir la LIJ en el aula, tal y como demandaban, entre otros, Hermida \& Cañón (2002); aunque habría que plantearse la proporción de géneros y la presencia de textos no literarios.

En lo que atañe al tema que nos ocupa, habría que reseñar que el empleo de escritos pensados para niños - ya sean fragmentos, ya textos completos - garantiza en gran medida que estos cumplen algunos de los elementos que Romero (2009, p. 194) señala como necesarios para trabajar la comprensión en los primeros ciclos de Educación Primaria: temas interesantes para el alumno (vinculados a sus conocimientos y experiencias), niveles gramaticales adecuados a su competencia lingüística y marcas temporales y espaciales pertinentes que faciliten la recreación de las descripciones y la secuenciación de lo sucedido.

\section{Las actividades para el trabajo de la comprensión lectora}

Pero los contenidos no lo son todo a la hora de trabajar la comprensión lectora, sin duda, las actividades propuestas constituyen un elemento fundamental para que el acercamiento a los textos que se propone al alumno resulte efectivo.

\subsection{Descripción general de las actividades}

Los tres manuales coinciden en proponer como primer paso la lectura del texto, ya sea realizada por el profesor, por los alumnos o bien oída desde su grabación en audio. Este elemento es algo que debe cuidarse, pues de una lectura expresiva correcta depende en gran medida la comprensión del texto.

\footnotetext{
${ }^{6}$ Por razones de espacio no se analiza dicha sección, de la que, no obstante, podemos precisar que suele enfocarse a la adquisición de rudimentos propios del lenguaje literario o adopta un tono historiográfico. En ella, en todos los casos, figuran autores que conforman el canon literario general y otros especializados en LIJ.

${ }^{7}$ Como podrá apreciarse en los anexos, en la selección de textos y autores tanto Edebé como Edelvives suelen recurrir a aquellos que editan bajo su sello, mientras que en la hecha por Anaya la procedencia es más variada.
} 
Igualmente, en los casos de Anaya (En línea) y Edelvives (Pixépolis), antes de la inserción del texto de lectura se incluyen un pequeño resumen de lo que luego se leerá y alguna pregunta relacionada con el contenido del texto. En Edebé (Píxel) no se ofrecen preguntas iniciales, pero a veces la actividad oral con la que dan comienzo las unidades guarda relación con lo trabajado como comprensión lectora, aunque dicha relación no es siempre evidente.

En cuanto a las actividades que tras la lectura deben realzarse, en el caso de Anaya, estas parten de varias preguntas sobre los contenidos del texto que se realizan de manera oral (personajes, sucesión de acciones y causas de las mismas) a las que siguen otras para elaborar por escrito, que guardan relación con las orales y suponen una reelaboración y argumentación de lo dicho; siguen luego otras cuestiones en las que a partir de lo leído el alumno debe pensar sobre aspectos concretos — personalidad de los protagonistas, por ejemplo- y reflejar por escrito sus ideas; también se ofrece la opción de manipular el texto, cambiándolo desde el punto de vista de quien lo cuenta, comenzándolo de otra forma, variar versos...; de igual modo se establece otro apartado en el que se solicita a través de una serie de cuestiones que se vincule lo visto con la propia realidad y finalmente se elabora una ficha de la lectura, en la que, según el género al que pertenezca el texto, el alumno debe recoger determinados datos bibliográficos, ofrecer el resumen, destacar versos o indicar qué fue lo más interesante ${ }^{8}$.

En Edebé, los ejercicios de comprensión parten de la elección de la respuesta correcta de entre un grupo de opciones a varias preguntas, para desde la selección hecha elaborar el resumen y terminar precisando qué se ha aprendido; siguen varias tareas para trabajar el vocabulario - a veces desde el punto de vista del significado en el texto, pero en otras ocasiones se adopta un enfoque gramatical que lleva a tratar conceptos como sinonimia y antonimia o composición de palabras - y se cierra el conjunto con la comparación en grupo de lo respondido ${ }^{9}$. En ocasiones se añade o se modifica la actividad final con un debate/diálogo sobre alguno de los aspectos reflejados en el texto que se conecta con las vivencias de los alumnos.

Si nos fijamos en Edelvives se aprecia que de manera general el conjunto de actividades se centra en el contenido del texto: determinación de personajes, evolución de los sucesos - a veces con viñetas que deben numerarse-, localización de expresiones $\mathrm{y}$ deducción de su significado ${ }^{10}$, selección de fragmentos y explicación de los mismos.

\footnotetext{
${ }^{8}$ Las preguntas se encabezan con los siguientes epígrafes: "Comprendo el texto", "Reflexiono sobre el texto", "Escribo sobre el texto", "Relaciono con mi mundo" y "Elaboro la ficha de lectura".

${ }^{9}$ Los apartados son "Eliges las respuestas y resumes", "Trabajas el vocabulario" y "Comparas respuestas" / "Hablas de..." / "Inventas una historia...". La denominación de estos apartados suele variar de unas unidades a otras, de acuerdo con el tono adoptado en el manual para titular los textos, ya que no se suele precisar cuándo se trabaja cada elemento, presentando los materiales como una invitación al alumno o caracterizando brevemente el material. Sirvan de ejemplo varios de los rótulos empleados en el libro de tercero para introducir la sección de lectura: "Lees una fábula", "Lees un recuerdo de un escritor", "Lees anotaciones", etc.

${ }^{10}$ Esta pregunta se ofrece bajo el rótulo de "Habilidad lectora".
}

ISL, vol. 5, 2016, págs. 19-35

ISNN: 2340-8685
Sánchez Hita, B (2016): Reading comprehension in Spanish language and literature manuals of the second cycle of Elementary Education, Investigaciones Sobre Lectura, 5, 19-35. 
Ahora bien, el modo en el que se propone alguna de estas preguntas hace necesario que el alumno reflexione realmente sobre lo que se le inquiere; se pide así que se trace el recorrido de un personaje sobre un plano o se le solicita que ofrezca argumentos sobre las causas de alguna decisión adoptada o suceso del relato. Asimismo, las actividades de comprensión suelen cerrarse con una pregunta abierta -que podría trabajarse oralmente- en la que se presenta una situación similar a la reflejada en la lectura para que los receptores muestren su opinión sobre un determinado aspecto.

Como puede apreciarse las tres ofertas analizadas tratan de conjugar algunas actividades orales con otras escritas con el objetivo de trabajar las habilidades lingüísticas básicas de manera combinada; sin embargo, existen diferencias entre lo propuesto por unos y otros, y así mientras que Anaya y Edelvives suelen ofrecer mayores posibilidades de manipulación del texto, Edebé tiende a emplear el escrito para el trabajo de cuestiones relacionadas con la gramática y la ampliación y reajuste del léxico de los alumnos.

\subsection{Las actividades a la luz del proceso interactivo y las fases de la comprensión lectora}

El modelo interactivo de comprensión lectora ${ }^{11}$ supone la relación continua en el proceso lector de los datos aportados por el texto y los conocimientos que posee el receptor del mismo. Se basa en la activación de lo sabido y archivado en la memoria a largo plazo con lo nuevo, a partir del establecimiento de hipótesis (anticipación, inferencia, etc.) que se van verificando mediante el empleo de la memoria a corto plazo, que permite retener ideas o conceptos e ir apreciando si son acertadas o no de acuerdo con lo contenido en el escrito, para una vez acabado el proceso reestructurar el conocimiento de partida del lector e incluir en la memoria a largo plazo nuevas informaciones que mejorarán las interacciones futuras (Galera, 2003, p. 234 y Cassany, Luna y Sanz, 1994, pp. 203-206). Si tenemos en cuentas las fases en las que se desarrolla la comprensión lectora: precomprensión, comprensión e interpretación - de las que la decodificación se sitúa como actividad de carácter mecánico que permite la primera aproximación al contenido- se aprecia cómo las tareas destinadas a la comprensión y a la interpretación son las que predominan en los libros analizados, sin que apenas existan elementos, más allá de algún resumen o pregunta breve, la imagen del propio texto, su disposición o las ilustraciones que lo acompañan que propicien el trabajo de la precomprensión. En este sentido, y siguiendo la propuesta de Romero (2009, pp. 195196) estimamos de notable importancia para favorecer la comprensión lectora el trabajo previo a la lectura en sí, esto es, el "acercamiento del texto mediante la motivación", elemento este donde el docente juega un papel clave y que permite adaptar el texto a los receptores a partir de las características particulares del grupo, se puede reflexionar sobre

\footnotetext{
${ }^{11}$ No se ofrece aquí la descripción de los modelos ascendentes (botton up) o descendentes (top-down) centrados en el lector y el texto respectivamente, para una caracterización general de los mismos remitimos a Galera (2003).
} 
el título y el posible desarrollo del texto (Romero, 2009, pp. 196), se puede trabajar sobre una imagen para preguntar qué palabras pueden aparecer en el texto o bien de qué puede tratar (Cassany et al., 1994, pp. 214-216) o utilizar cualquier otro elementos que posibilite un trabajo explícito anterior a la lectura. En definitiva, consideramos interesante que de manera previa a la actividad de lectura se activen los conocimientos del alumno, para a partir de estos favorecer los procesos que tendrá que poner en marcha durante la recepción de lo escrito y que lo llevarán, como ya se apuntó, a establecer hipótesis e ir reelaborando sus ideas iniciales. Es cierto que en los libros consultados hay elementos que ayudan a iniciar el proceso de lectura, pero son por lo general breves y a veces no sobrepasan el mero resumen introductorio.

Como precisa Tapia (2005, p. 64) "la motivación y los procesos son los dos pilares sobre los que se apoya la comprensión", por ello no solo debe atenderse al segundo de los pasos, que llevaría al establecimiento de inferencias y verificaciones, sino que habría que facilitar el acceso inicial a lo escrito, para lo que resulta necesario crear un entorno de lectura adecuado a partir de la formulación del propósito de la lectura y la activación de los conocimientos previos (p. 82).

\section{A modo de conclusión}

A través del somero recorrido hecho por los contenidos empleados para la lectura en los manuales del segundo ciclo de Educación Primaria en Andalucía se ha podido constatar que son los géneros literarios, y especialmente el género narrativo, los que predominan como materiales ofrecidos al alumno. En todos los casos se recurre a las producciones de autores de LIJ, así como a adaptaciones de otras obras no escritas específicamente para niños, algo que resulta sin duda interesante por la adecuación de los escritos que supone este hecho. No obstante, no debería descuidarse el trabajo con una variedad significativa de textos - tanto literarios, como de uso social o de disciplinas diferentes ámbitos de conocimiento- que contribuya a mejorar las capacidades de comprensión lectora del alumno.

Igualmente, en lo que se refiere a las actividades, aunque es cierto que en general se ha superado la tendencia a trabajar únicamente la comprensión literal, hay aspectos que podrían mejorar la interpretación de los textos y que tienen que ver con la presentación de los mismos; pues un correcto trabajo previo a la lectura ayudaría a la recepción del escrito y a la valoración e integración del contenido en los esquemas de conocimiento personales.

Se hace así evidente que en la consecución de un correcto desarrollo de la comprensión lectora el profesorado juega un papel clave, de ahí la necesidad no solo de seleccionar los materiales, sino de trabajarlos adecuadamente, entendiendo que como

ISL, vol. 5, 2016, págs. 19-35 ISNN: 2340-8685
Sánchez Hita, B (2016): Reading comprehension in Spanish language and literature manuals of the second cycle of Elementary Education, Investigaciones Sobre Lectura, 5, 19-35. 
señala García (2002, p. 256) el libro es ante todo "un complemento eficaz a su tarea", pero que esta debe basarse en los alumnos, lo que hace necesario adecuar lo ofrecido a ellos y evitar que las lecturas se conviertan en una "actividad rutinaria" e "impositiva", aspectos estos que creemos que pueden superarse con un buen trabajo aproximación al escrito y con la combinación de actividades que fomenten su comprensión, para lo que estimamos de gran utilidad algunas de las propuestas que pasan por interpretar lo dicho y plasmarlo en otros formatos - recorrido de los personajes en un plano-, selección de la respuesta correcta entre varias y elaboración de resumen, así como la manipulación del escrito para cambiar el final, incluir algún personaje o modificar versos. De igual modo, la colaboración entre los alumnos puede facilitar el proceso, por ello otros elementos como la disposición de la clase o la posibilidad de realizar los ejercicios en gran grupo y pequeños grupos es algo que tampoco debe ser descuidado ${ }^{12}$.

\section{Bibliografía ${ }^{13}$ :}

Cassany, D., Luna, M. y Sanz, G. (1994). Enseñar lengua. Barcelona: Graó.

Galera, F. (2008). La lectoescritura. Métodos y procesos. En A. Mendoza (Coord.), Didáctica de la lengua y la literatura para primaria (pp. 217-261). Madrid: Prentice Hall.

García, J. (2002). Los materiales para la lectura en el aula. En A. Mendoza, (Dir.), La seducción de la lectura en edades tempranas (pp. 253-282). Madrid: Ministerio de Educación Cultura y Deporte. Recuperado el 9 de enero de 2016 de https://sede.educacion.gob.es/publiventa/la-seduccion-de-la-lectura-en-edadestempranas/ensenanza/10997

Gracia, M. de, Jiménez, R., Rodrigo, Mª J., Romero, M. F., Salvador, A. y Sibón, T. G., (2009). La comprensión lectora: propuestas para la atención a la diversidad en el aula. La comprensión de textos escritos en Educación Primaria. Madrid: Visión Libros.

Hermida, C. y Cañón, M. (2002). Conformar el canon literario escolar. Cuadernos de Literatura Infantil y Juvenil, 150, 7-12. Recuperado el 9 de enero de 2016 de file://C:/Users/USUARIO/Downloads/clij-cuadernos-de-literatura-infantil-yjuvenil-136.pdf

Ley Orgánica 2/2006, de 3 de mayo, de Educación (LOE). Boletín Oficial del Estado, n ${ }^{\circ}$ 106, 2006, 4 de mayo.

\footnotetext{
${ }^{12}$ Sobre este último aspecto resulta de utilidad el trabajo de Romero (2009).

${ }^{13}$ No se han incluido aquí las referencias a los manuales utilizados, pues se aporta la información fundamental en el cuerpo del texto.
} 
LEY ORGANICA 8/2013, de 9 de diciembre para la mejora de la calidad educativa (LOMCE). Boletín Oficial del Estado, n 295, 2013, 10 de diciembre.

Mendoza, A. (Coord.). (2008). Didáctica de la lengua y la literatura para primaria. Madrid: Prentice Hall.

- (2002). La renovación del canon escolar: la integración de la literatura infantil y juvenil en la formación literaria. En M. C. Hoyos Ragel et al., (Eds.), El reto de la lectura en el siglo XXI (pp. 21-38). Granada: Grupo Editorial Universitario.

Mendoza, A., López, A. y Martos, E. (1996). Didáctica de la Lengua para la enseñanza primaria y secundaria. Madrid: Akal.

Romero, F. (2009). Acceso a las competencias básicas desde la lectoescritura. Tabanque. Revista de Pedagogía, 22, 191-204. Recuperado el 9 de enero de 2016 de file://C:/Users/USUARIO/Downloads/DialnetAccesoALasCompetenciasBasicasEducativasDesdeLaLect-3290589\%20(2).pdf

Tapia, J. A. (2005). Claves para la enseñanza de la comprensión lectora. Revista de educación, número extraordinario 2005, 63-93. Recuperado el 9 de enero de 2016 de

http://www.oei.es/fomentolectura/claves_ensenanza_comprension_lectora_alons o_tapia.pdf

Tejerina, I. (Dir.). (2004). Lecturas y lectores en la ESO. Una investigación educativa. Santander: Ediciones de la Consejería de Educación del Gobierno de Cantabria. Recuperado el 9 de enero de 2016 de http://www.cervantesvirtual.com/obra-visordin/lecturas-y-lectores-en-la-eso-una-investigacin-educativa-0/html/ 
ANEXO 1. Contenidos de la sección "Lectura" en los manuales analizados.

Tabla 1. Contenidos de la sección "Lectura" de ANAYA. Tercer curso

\begin{tabular}{|c|c|c|c|c|}
\hline \multicolumn{5}{|c|}{ ANAYA. EN LÍNEA. TERCER CURSO } \\
\hline Unidad & Género & Título de la lectura & Obra y Editorial & Autor \\
\hline 1 & Narrativa & La flauta mágica & 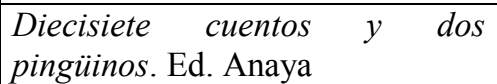 & Daniel Nesquens \\
\hline 2 & Narrativa & Gagrobatz & $\begin{array}{l}\text { Cornelia Funke cuenta cuentos } \\
\text { sobre devoralibros, fantasmas de } \\
\text { desvanes y otros héroes. EDAF }\end{array}$ & Cornelia Funke \\
\hline 3 & Divulgativo & Alimentos lejanos & $\begin{array}{l}\text { Todas las respuestas a las } \\
\text { preguntas que nunca te has hecho. } \\
\text { Ed. Faktoría } \mathrm{K} \text { de Libros }\end{array}$ & $\begin{array}{l}\text { Philippe } \\
\text { Nessmann }\end{array}$ \\
\hline 4 & Narrativa & Fortunato & $\begin{array}{l}\text { Querido Rey de España. Ed. } \\
\text { Edelvives }\end{array}$ & $\begin{array}{l}\text { Jordi Sierra i } \\
\text { Fabra }\end{array}$ \\
\hline 5 & Poesía & $\begin{array}{l}\text { La ciudad [incluye dos } \\
\text { poemas]. } \\
\text { 1. Mi ciudad salvaje. } \\
\text { Primer verso: "Mi } \\
\text { plaza despierta" } \\
\text { 2. Estrellas de feria. } \\
\text { Primer verso: "El } \\
\text { Sol" } \\
\end{array}$ & $\begin{array}{l}\text { Ciudad laberinto. Kalandraka. } \\
\text { Ediciones Andalucía }\end{array}$ & Pedro Mañas \\
\hline 6 & Narrativa & Duendes & En Viriviví. Ed. Anaya & Consuelo Armijo \\
\hline 7 & Narrativa & Una bicicleta oxidada & La bicicleta de Selva. Ed. Anaya & $\begin{array}{l}\text { Mónica } \\
\text { Rodríguez }\end{array}$ \\
\hline 8 & Divulgativo & Plantas que muerden & ¿Qué sabes de las plantas? SM & $\begin{array}{l}\text { Juan Ignacio } \\
\text { Medina y Félix } \\
\text { Moreno }\end{array}$ \\
\hline 9 & Poesía & $\begin{array}{l}\text { Una luna constipada } \\
\text { [incluye un poema]: } \\
\text { Luna enferma. Primer } \\
\text { verso: "la Luna está } \\
\text { enferma" }\end{array}$ & Tambores de paz. Ed. Anaya & $\begin{array}{l}\text { José González } \\
\text { Torices }\end{array}$ \\
\hline 10 & Narrativa & $\begin{array}{l}\text { El estudiante y el } \\
\text { campesino }\end{array}$ & Este pícaro mundo. Ed. Anaya & Ana María Shua \\
\hline 11 & Teatro & El Teatro de la Ilusión & ¡Siempre toca! Ed. Bruño & $\begin{array}{l}\text { Montserrat del } \\
\text { Amo }\end{array}$ \\
\hline 12 & Poesía & $\begin{array}{l}\text { El mar [incluye dos } \\
\text { poemas] } \\
\text { 1. Va la mar. Primer } \\
\text { verso: "Va la mar } \\
\text { desmelenada". } \\
\text { 2. Canción. Primer } \\
\text { verso: "Te pinto de } \\
\text { timonel". }\end{array}$ & $\begin{array}{l}\text { Versos de colores. Ajonjolí. Ed. } \\
\text { Hiperión }\end{array}$ & Carmen Gil \\
\hline
\end{tabular}

Sánchez Hita, B (2016): Reading comprehension in Spanish language and literature manuals of the second cycle of Elementary Education, Investigaciones Sobre Lectura, 5, 19-35.
ISL, vol. 5, 2016, págs. 19-35

ISNN: $2340-8685$ 
Tabla 2. Contenidos de la sección "Lectura" de ANAYA. Cuarto curso

\begin{tabular}{|c|c|c|c|c|}
\hline \multicolumn{5}{|c|}{ ANAYA. EN LÍNEA. TERCER CURSO } \\
\hline Unidad & Género & Título de la lectura & Obra y Editorial & Autor \\
\hline 1 & Narrativa & El miedo de marcos & $\begin{array}{l}\text { Un problema con patas. Ed. } \\
\text { Edelvives }\end{array}$ & Marinella Terzi \\
\hline 2 & Narrativa & Una visita inesperada & $\begin{array}{l}\text { La cueva del corazón. Ed. } \\
\text { Anaya }\end{array}$ & Ana Alonso \\
\hline 3 & Divulgativo & Nuestros animales & $\begin{array}{l}\text { El viaje de Livingstone. Ed. } \\
\text { Magisterio Español }\end{array}$ & $\begin{array}{l}\text { Piero Ventura, } \\
\text { Gian Carlo } \\
\text { Ceserani } \\
\end{array}$ \\
\hline 4 & Poesía & $\begin{array}{l}\text { El Concierto. En } \\
\text { sombra mayor. Primer } \\
\text { verso: "Hoy los ratones } \\
\text { ensayan". }\end{array}$ & $\begin{array}{l}\text { La luna lleva un silencio. Ed. } \\
\text { Anaya }\end{array}$ & $\begin{array}{l}\text { María Cristina } \\
\text { Ramos Guzmán }\end{array}$ \\
\hline 5 & Teatro & Un ratoncillo atrapado & $\begin{array}{l}\text { Cuentos y teatrillos «en verde». } \\
\text { Ed. Narcea. (Texto adaptado) }\end{array}$ & Isabel Agüera \\
\hline 6 & Narración & $\begin{array}{l}\text { Don Quijote de la } \\
\text { Mancha }\end{array}$ & $\begin{array}{l}\text { El Quijote contado a los niños. } \\
\text { Ed. Edebé }\end{array}$ & $\begin{array}{l}\text { Rosa Navarro } \\
\text { Durán }\end{array}$ \\
\hline 7 & Divulgativo & Expediciones a África & $\begin{array}{l}\text { Los exploradores a través del } \\
\text { tiempo. Ed. Anaya }\end{array}$ & Fiona Macdonald \\
\hline 8 & Narración & Una isla muy original & La guía fantástica. Ed. Anaya & Joles Sennell \\
\hline 9 & Narración & $\begin{array}{l}\text { Una pandilla de } \\
\text { números }\end{array}$ & Días de clase. Ed. Anaya & Daniel Nesquens \\
\hline 10 & Poesía & $\begin{array}{l}\text { La luna y la sombra } \\
\text { 1. La luna. Primer } \\
\text { verso: "tiene la } \\
\text { misma cara que } \\
\text { el reloj del salón" } \\
\text { 2. Mi sobra. Primer } \\
\text { verso: "Mi } \\
\text { sombra es muy } \\
\text { grande y va } \\
\text { siempre } \\
\text { conmigo" }\end{array}$ & $\begin{array}{l}\text { Jardín de versos para niños. Ed. } \\
\text { Hiperión }\end{array}$ & $\begin{array}{l}\text { Robert Louis } \\
\text { Stevenson }\end{array}$ \\
\hline 11 & Poesía & $\begin{array}{l}\text { Cambios de estación } \\
\text { 1. Estaciones. } \\
\text { Primer verso: } \\
\text { "¡Primavera"! } \\
\text { 2. } \\
\text { Agosto. Primer } \\
\text { verso: "En } \\
\text { agosto" } \\
\end{array}$ & $\begin{array}{l}\text { Ciudad laberinto. Ciudad K de } \\
\text { Libros. Kalandraka Ediciones }\end{array}$ & Pedro Mañas \\
\hline 12 & Teatro & Los animales conversan & Animaladas. Ed. Anaya & Rafael Alcaraz \\
\hline
\end{tabular}

ISL, vol. 5, 2016, págs. 19-35 ISNN: 2340-8685
Sánchez Hita, B (2016): Reading comprehension in Spanish language and literature manuals of the second cycle of Elementary Education, Investigaciones Sobre Lectura, 5, 19-35. 
Tabla 3. Contenidos de la sección "Lectura" de EDEBÉ. Tercer curso

\begin{tabular}{|c|c|c|c|c|}
\hline \multicolumn{5}{|c|}{ EDEBÉ. PÍXEL. TERCER CURSO } \\
\hline Unidad & Género & Título de la lectura & Obra y Editorial & Autor \\
\hline 1 & Narrativa & El ciervo de la fuente & $\begin{array}{l}\text { Fábulas contadas a los niños. } \\
\text { Colección Clásicos contados a } \\
\text { los niños. Edebé }\end{array}$ & $\begin{array}{l}\text { Rosa Navarro } \\
\text { Durán } \\
\text { (Adaptadora) }\end{array}$ \\
\hline 2 & Narrativa & El tío de las vistas & $\begin{array}{l}\text { Platero y yo, de Juan Ramón } \\
\text { Jiménez contado a los niños. } \\
\text { Edebé }\end{array}$ & $\begin{array}{l}\text { Rosa Navarro } \\
\text { Durán } \\
\text { (Adaptadora) }\end{array}$ \\
\hline 3 & Narrativa & $\begin{array}{l}\text { El príncipe } \\
\text { desencantado }\end{array}$ & $\begin{array}{l}\text { La noche que tuve un monstruo } \\
\text { encerrado en el armario. Edebé. } \\
\text { Colección Tucán naranja }\end{array}$ & $\begin{array}{l}\text { Gabriel García de } \\
\text { Oro }\end{array}$ \\
\hline 4 & Narrativa & Las pléyades & $\begin{array}{l}\text { Siete noches con Paula. } \\
\text { Colección Tucán. Editorial } \\
\text { Edebé }\end{array}$ & $\begin{array}{l}\text { Patxi Zubizarreta y } \\
\text { Juan Cruz } \\
\text { Iguerabide }\end{array}$ \\
\hline 5 & Narrativa & Efectos secundarios & $\begin{array}{l}\text { El año de los piojos. Colección } \\
\text { Tucán. Editorial Edebé }\end{array}$ & David Nel-lo \\
\hline 6 & Narrativa & $\begin{array}{l}\text { El regreso de Odiseo al } \\
\text { hogar }\end{array}$ & $\begin{array}{l}\text { Disfruta con la mitología. } \\
\text { Editorial Edebé }\end{array}$ & Berta García \\
\hline 7 & Narrativa & El genio Eugenio & $\begin{array}{l}\text { Eugenio: un genio con mal } \\
\text { genio. Colección Tucán. } \\
\text { Editorial Edebé }\end{array}$ & Enric Lluch \\
\hline 8 & Narrativa & $\begin{array}{l}\text { El joven pastor y las } \\
\text { ovejas }\end{array}$ & $\begin{array}{l}\text { Fábulas contadas a los niños. } \\
\text { Colección Clásicos contados a } \\
\text { los niños. Edebé }\end{array}$ & $\begin{array}{l}\text { Rosa Navarro } \\
\text { Durán } \\
\text { (Adaptadora) }\end{array}$ \\
\hline 9 & Narrativa & $\begin{array}{l}\text { ¿Quién es el rey de los } \\
\text { pájaros? }\end{array}$ & $\begin{array}{l}\text { Cuentos japoneses. Editorial } \\
\text { Edebé }\end{array}$ & $\begin{array}{l}\text { Anna Gasol y } \\
\text { Teresa Blanch } \\
\text { (Compiladoras) }\end{array}$ \\
\hline 10 & Poesía & $\begin{array}{l}\text { Las bodas de piojos y } \\
\text { pulgas }\end{array}$ & - & Popular \\
\hline 11 & Narrativa & $\begin{array}{l}\text { El caso de la serpiente } \\
\text { misteriosa }\end{array}$ & $\begin{array}{l}\text { Doctor Rus. Col. Tucán. } \\
\text { Editorial Edebé }\end{array}$ & Gloria Sánchez \\
\hline 12 & $\begin{array}{l}\text { Divulgati } \\
\text { vo }\end{array}$ & $\begin{array}{l}\text { Curiosidades de la } \\
\text { naturaleza }\end{array}$ & ( & - \\
\hline 13 & Narrativa & $\begin{array}{l}\text { La nueva banda } \\
\text { municipal }\end{array}$ & $\begin{array}{l}\text { El trompetista y la Luna. Col. } \\
\text { Tucán. Editorial Edebé }\end{array}$ & Xelis de Toro \\
\hline 14 & $\begin{array}{l}\text { Divulgati } \\
\text { vo }\end{array}$ & $\begin{array}{l}\text { Preguntas a Luis Miguel } \\
\text { Domínguez Mencía, } \\
\text { naturalista }\end{array}$ & - & - \\
\hline 15 & Poesía & $\begin{array}{l}\text { Amapola "Novia del } \\
\text { campo, amapola," }\end{array}$ & - & $\begin{array}{l}\text { Juan Ramón } \\
\text { Jiménez }\end{array}$ \\
\hline
\end{tabular}

Sánchez Hita, B (2016): Reading comprehension in Spanish language and literature manuals of the second cycle of Elementary Education, Investigaciones Sobre Lectura, 5, 19-35.
ISL, vol. 5, 2016, págs. 19-35

ISNN: 2340-8685 
Tabla 4. Contenidos de la sección "Lectura" de EDEBÉ. Cuarto curso

\begin{tabular}{|c|c|c|c|c|}
\hline \multicolumn{5}{|c|}{ EDEBÉ. PÍXEL. CUARTO CURSO } \\
\hline Unidad & Género & Título de la lectura & Obra y Editorial & Autor \\
\hline 1 & Narrativa & Un sueño muy raro & $\begin{array}{l}\text { Jon y la máquina del tiempo. Colección } \\
\text { Tucán. Editorial Edebé }\end{array}$ & $\begin{array}{l}\text { Roberto } \\
\text { Santiago }\end{array}$ \\
\hline 2 & Narrativa & $\begin{array}{l}\text { La actuación de } \\
\text { Tim }\end{array}$ & $\begin{array}{l}\text { Tim, nariz de payaso. Colección Tucán. } \\
\text { Editorial Edebé. }\end{array}$ & Anna Cabeza \\
\hline 3 & Narrativa & Un espejo mágico & $\begin{array}{l}\text { El espejo del futuro. Colección Tucán. } \\
\text { Editorial Edebé }\end{array}$ & $\begin{array}{l}\text { Jordi Sierra y } \\
\text { Fabra }\end{array}$ \\
\hline 4 & Narrativa & $\begin{array}{l}\text { Las vacaciones de } \\
\text { Silvia }\end{array}$ & $\begin{array}{l}\text { El zoo del verano. Colección Tucán. } \\
\text { Editorial Edebé }\end{array}$ & Isabel Córdova \\
\hline 5 & Poesía & $\begin{array}{l}\text { La cojita. Primer } \\
\text { verso: "La niña } \\
\text { sonríe: ¡Espera" }\end{array}$ & ${ }^{2}$ & $\begin{array}{l}\text { Juan Ramón } \\
\text { Jiménez }\end{array}$ \\
\hline 6 & Narrativa & Florentino "Nolosé" & $\begin{array}{l}\text { Cuentos para dormir a la abuela. } \\
\text { Colección Tucán. Editorial Edebé }\end{array}$ & $\begin{array}{l}\text { Antonio } \\
\text { Manuel } \\
\text { Fabregat }\end{array}$ \\
\hline 7 & Narrativa & $\begin{array}{l}\text { Un postre } \\
\text { accidentado }\end{array}$ & $\begin{array}{l}\text { Música a los postres. Colección Tucán. } \\
\text { Editorial Edebé }\end{array}$ & $\begin{array}{l}\text { Ana Martín } \\
\text { Pérez }\end{array}$ \\
\hline 8 & Narrativa & Me gusta el fútbol & $\begin{array}{l}\text { Mi hermano el genio. Colección Tucán. } \\
\text { Editorial Edebé }\end{array}$ & $\begin{array}{l}\text { Rodrigo Muñoz } \\
\text { Ávila }\end{array}$ \\
\hline 9 & Narrativa & $\begin{array}{l}\text { Todo sobre mi } \\
\text { familia }\end{array}$ & $\begin{array}{l}\text { Donde nunca es invierno. Colección } \\
\text { Tucán. Editorial Edebé }\end{array}$ & $\begin{array}{l}\text { Claudia } \\
\text { Larraguibel }\end{array}$ \\
\hline 10 & Divulgativo & $\begin{array}{l}\text { Guía del buen } \\
\text { peatón }\end{array}$ & 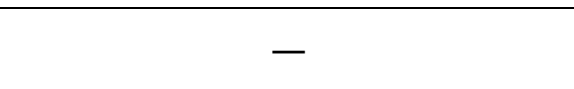 & - \\
\hline 11 & Narrativa & $\begin{array}{l}\text { Un regalo para } \\
\text { Bilulú }\end{array}$ & - & $\begin{array}{l}\text { Luxenburgo: } \\
\text { Oficina de } \\
\text { Publicaciones } \\
\text { Oficiales de las } \\
\text { Comunidades } \\
\text { Europeas }\end{array}$ \\
\hline 12 & Narrativa & Voy sobre ruedas & $\begin{array}{l}\text { Voy sobre ruedas. Colección Tucán } \\
\text { naranja. Editorial Edebé }\end{array}$ & $\begin{array}{l}\text { Xabier } \\
\text { Mendiguen } \\
\end{array}$ \\
\hline 13 & Divulgativo & $\begin{array}{l}\text { ¿Cuánto tarda en } \\
\text { degradarse una } \\
\text { bolsa de plástico? }\end{array}$ & g h & - \\
\hline 14 & Divulgativo & $\begin{array}{l}\text { Un nuevo } \\
\text { continente }\end{array}$ & - & - \\
\hline 15 & Poesía & $\begin{array}{ll}\text { 1. } & \text { El Lagarto } \\
& \text { está llorando. } \\
& \text { Primer verso: } \\
& \text { "El lagarto } \\
& \text { está llorando } \\
\text { 2. } & \text { Mariposa. } \\
& \text { Primer verso: } \\
& \text { "Mariposa } \\
& \text { del aire". } \\
\text { 3. } & \text { Cancioncilla } \\
& \text { sevillana. } \\
& \text { Primer verso: } \\
& \text { "Amanecía" }\end{array}$ & - & $\begin{array}{l}\text { Federico García } \\
\text { Lorca }\end{array}$ \\
\hline
\end{tabular}

ISL, vol. 5, 2016, págs. 19-35 ISNN: 2340-8685
Sánchez Hita, B (2016): Reading comprehension in Spanish language and literature manuals of the second cycle of Elementary Education, Investigaciones Sobre Lectura, 5, 19-35. 
Tabla 5. Contenidos de la sección "Lectura" de EDELVIVES. Tercer curso

\begin{tabular}{|c|l|l|l|}
\hline \multicolumn{4}{|c|}{ EDELVIVES PIXÉPOLIS. TERCER CURSO } \\
\hline Tema & \multicolumn{1}{|c|}{ Género } & \multicolumn{1}{c|}{ Título de la lectura } & \multicolumn{1}{c|}{ Autor } \\
\hline 0 & Narrativa & ¿Seremos amigos? & Antonio Vicente \\
\hline 1 & Narrativa & Un regalo con mucho sentido & Roberto Aliaga \\
\hline 2 & Narrativa & Aviso a todos los animales & Alfredo Gómez Cerdá \\
\hline 3 & Narrativa & Un nido de fantasmas & Pepe Maestro \\
\hline 4 & Narrativa & Una fiesta para el árbol & José García Oliva \\
\hline 5 & Narrativa & El dibujo más grande del mundo & Antonio Vicente \\
\hline 6 & Narrativa & Una extraña nube & Pablo Albo \\
\hline 7 & Narrativa & Amor en botella & Roberto Aliaga \\
\hline 8 & Narrativa & Una ciudad, un pueblo, un faro & Alfredo Gómez Cerdá \\
\hline 9 & Narrativa & Un pueblo sin nombre & Pepe Maestro \\
\hline 10 & Narrativa & Trabajo rico: pizza en equipo & José García Oliva \\
\hline 11 & Narrativa & Una noticia increíble & Antonio Vicente \\
\hline 12 & Narrativa & Una moneda con historia & Pablo Albo \\
\hline
\end{tabular}

Tabla 6. Contenidos de la sección "Lectura" de EDELVIVES. Cuarto curso

\begin{tabular}{|c|l|l|l|}
\hline \multicolumn{5}{|c|}{ EDELVIVES PIXÉPOLIS. CUARTO CURSO } \\
\hline Tema & Género & \multicolumn{1}{c|}{ Título de la lectura } & \multicolumn{1}{c|}{ Autor } \\
\hline 0 & Narrativa & Mi abuela felisa & Antonio Vicente \\
\hline 1 & Narrativa & Una mascota glotona & Roberto Aliaga \\
\hline 2 & Narrativa & Buenaventura hijo, nieto, bisnieto & Alfredo Gómez Cerdá \\
\hline 3 & Narrativa & La dieta de Renato & Pepe Maestro \\
\hline 4 & Narrativa & La competición en el Gran Bosque & José García Oliva \\
\hline 5 & Narrativa & Todo se transforma & Antonio Vicente \\
\hline 6 & Narrativa & Por un zumbido de mosca & Pablo Albo \\
\hline 7 & Narrativa & Escrito a máquina & Roberto Aliaga \\
\hline 8 & Narrativa & Una lección en la montaña & Alfredo Gómez Cerdá \\
\hline 9 & Narrativa & Benito Miraflores, vecino de Solariegos & Pepe Maestro \\
\hline 10 & Narrativa & La aventura de Montehermoso & José García Oliva \\
\hline 11 & Narrativa & Un censo cavernícola & Antonio Vicente \\
\hline 12 & Narrativa & Un señor raro de otro tiempo & Pablo Albo \\
\hline
\end{tabular}

